Poznańskie Studia Teologiczne 30(2016), s. 159-171. doi: $10.14746 /$ pst.2016.30.07

\author{
Ireneusz Celary ${ }^{1}$ \\ Uniwersytet Śląski w Katowicach \\ Wydział Teologiczny
}

\title{
Die Hilfe für kranke und alte Menschen in der postmodernen Gesellschaft nach Papst Franziskus
}

Das Leben der kranken und alten Menschen in der heutigen postmodernen Welt stellt kein Randproblem dar, vielmehr eine große Herausforderung für sie selbst, für ihre Familien und auch für die pastoralen Bemühungen der Kirche. Im seinem Apostolischen Schreiben Evangelii gaudium schreibt Papst Franziskus, dass: „Trotz der ganzen laizistischen Strömung, die die Gesellschaft überschwemmt, ist die Kirche in vielen Ländern [...] in der öffentlichen Meinung eine glaubwürdige Einrichtung, zuverlässig in Bezug auf den Bereich der Solidarität und der Sorge für die am meisten Bedürftigen”. „Wir dürfen [auch heute - Anmerkung des Autors] nicht übersehen, dass sich in den Städten [...] die Preisgabe Alter und Kranker [...] leicht vermehren" (EG 75). Darum ist Franziskus „unendlich dankbar für den Einsatz aller, die in der Kirche arbeiten”.

Ich möchte mich jetzt - schreibt er weiter - nicht dabei aufhalten, die Aktivitäten der verschiedenen in der Seelsorge Tätigen darzustellen, von den Bischöfen bis hin zum bescheidensten und am meisten verborgenen der kirchlichen Dienste. [...] Doch zuallererst und der Gerechtigkeit halber muss ich sagen, dass der Beitrag der Kirche in der heutigen Welt enorm ist. Unser Schmerz und unsere Scham wegen der Sünden einiger Glieder der Kirche und wegen unserer eigenen Sünden dürfen nicht vergessen lassen, wie viele Christen ihr Leben aus Liebe hingeben. Sie helfen vielen Menschen, sich in unsicheren Krankenhäusern behandeln zu lassen oder dort in Frieden zu sterben; [...] sie kümmern sich um alte Menschen, die von allen verlassen sind; sie versuchen, in feindlicher Umgebung Werte zu vermitteln oder sie widmen sich auf viele andere Arten, die die grenzenlose Liebe zur Menschheit deutlich machen, die der Mensch gewordene Gott uns eingegeben hat. Ich danke für das schöne Beispiel, das viele Christen mir geben, die ihr Leben und ihre Zeit freudig hingeben. Dieses Zeugnis tut mir sehr gut und unterstützt mich in meinem persönlichen Stre-

\footnotetext{
${ }^{1}$ Prezbiter, dr hab. prof. UŚ w Katedrze Teologii Pastoralnej, Liturgiki, Homiletyki i Katechetyki na Wydziale Teologicznym UŚ w Katowicach, e-mail: icelary@op.pl.

${ }^{2}$ Franciszek, Adhortacja apostolska o głoszeniu Ewangelii we współczesnym świecie „Evangelii gaudium”, Częstochowa 2003, Nr. 65 (ab hier: EG).
} 
ben, den Egoismus zu überwinden, um mich noch intensiver meiner Aufgabe widmen zu können (EG 76).

Der folgende Artikel gibt uns Mahnungen des Papstes Franziskus zur Lage der älteren und kranken Menschen in der Welt von heute. Folgende Themen werden behandelt: I. Die Kompetenz der Gesellschaft für kranke und alte Menschen; II. Die Bedeutung der christlichen Gemeinde für die kranken und alten Menschen; III. Die Ziele des Seelsorgegesprächs.

\section{Die Kompetenz der Gesellschaft}

Das Faktum der Kleinfamilien, die postmoderne Wohnungssituation, der Mangel an Pflegekräften und die Berufstätigkeit vieler Frauen sind die wesentlichen Gründe dafür, dass man sich um die leidenden und betagten Personen nicht mehr so kümmern kann, wie es ihren Bedürfnissen entspräche ${ }^{3}$. Unter den gegenwärtigen Lebensverhältnissen können - nach Papst Franziskus - jene, die einer dauernden Betreuung und Versorgung bedürfen, nur zeitlich begrenzt in der Familie zu behalten werden ${ }^{4}$. In den Strapazen des postmodernen Lebens (vgl. EG 52-53) fühlen sich viele solchen zusätzlichen Beeinträchtigungen nicht gewachsen; deswegen übergeben sie die Zuständigkeit für die Kranken und Alten den Krankenhäusern, Alten- und Pflegeheimen, manchmal auch ohne überhaupt andere Optionen ernsthaft in Erwägung ziehen ${ }^{6}$.

${ }^{3}$ Vgl. M.N. Ebertz, Christwerden - in welcher Gesellschaft? Relativiesierungsgeneratoren in der deutschen Gegenwartsgesellschaft, in: Christwerden im Kulturwandel. Analysen, Themen und Optionen für Religionspädagogik und Praktische Theologie, hrsg. T. Schreijäck, Freiburg i. Br. 2001, S. 41-42; W. Przygoda, Teologia cierpienia i choroby, „Śląskie Studia Historyczno-Teologiczne” 33(2000), S. 258; Ders., Postuga charytatywna Kościoła wobec osób niepetnosprawnych, „Homo Dei” 74(2004), Nr 1, S. 66-70.

${ }^{4}$ Vgl. Franciszek, Najbliższy szpital, „L'Osservatore Romano” 36 (2015), Nr. 7-8, S. 48 (ab hier: OsRomPol); Ders., „Musimy się bronić przed kulturq odrzucania”. Spotkanie z ludźmi ubogimi, starymi i niepetnosprawnymi, OsRomPol 36 (2015), Nr. 7-8, S. 28-29; Ders., ,Wielkie bogactwo społeczne”. Msza św. w parku Los Samanes w Guayaquil (06.07.2015), OsRomPol 36 (2015), Nr. 7-8, S. 7.

5 Vgl. Franciszek, „Dzieci i dziadkowie sq nadzieja ludu”. Przemówienie do członków włoskiego Ruchu na rzecz Życia (11.04.2014), OsRomPol 35 (2014), Nr. 3-4, S. 28; A. Wollbold, Handbuch der Gemeindepastoral, Regensburg 2004, S. 394-395.

6 Vgl. Franciszek, ,Najcięższa chorobq, na jakq sq narażone osoby starsze, jest opuszczenie”. Przesłanie z okazji 20-lecia Papieskiej Akademii „Pro Vita”, OsRomPol 35 (2014), Nr. 3-4, 27-28; W. Przygoda, Die karitative Praxis der Kirche in Polen am Anfang des 21. Jahrhunderts, in: Pastoral-theologische Hefte, Bd. 1, hrsg. M. Polak, T. Kowalczyk, Wien-Gniezno 2008, S. 95-96; J. Strojnowski, Choroba, in: Encyklopedia katolicka, Bd. 3, Lublin 1993, Folge 232-235; Z. Pietrasiński, Rozwój dorostych, in: Wprowadzenie do andragogiki, hrsg. T. Wujek, Radom 1996, S. 29-31; K. Koch, Die Kirche Gottes. Gemeinschaft im Geheimnis des Glaubens, Augsburg 2007, S. 216-217; T. Wielebski, Duszpasterska postuga Kościoła w szpitalach i hospicjach, „Roczniki Teologiczne Warszawsko-Praskie” 3(2002), S. 265-298. 
Hier spielen selbstverständlich - wie es schon früher Papst Johannes Paul II. sehr oft gezeigt hat - die allgemeinen Gewohnheiten und die öffentliche Anschauung eine wesentliche Bestimmung: Hätte man sich zumindest bis zur Zeit des Ersten Weltkriegs harter Kritik ausgesetzt, wenn ein Familienmitglied oder jemand, der einer Familie eng verbunden war, in Alter und Krankheit nicht von ihr betreut worden wäre, so ist es heute für viele schon selbstverständlich, dass Fremde diese Aufgabe übernehmen ${ }^{7}$. Weil es so üblich geworden ist, macht man sich - nach Franziskus - wenig Gedanken darüber, dass eine noch so perfekte medizinische und physische Versorgung nicht genügt, um jenes Gefühl der Geborgenheit und der Sicherheit zu geben, das man braucht, um Krankheit, Schwäche und Gebrechlichkeit gelassen annehmen zu können ${ }^{8}$.

Im Apostolischen Schreiben Evangelii gaudium stellt Papst Franziskus nachdrücklich fest: Wir müssten uns auch unter vielem anderen mehr um das geistige und seelische Wohl der Hilfsbedürftigen kümmern, wenn wir von Humanität nicht nur sprechen, sondern diese wirklich human leben wollen (vgl. EG 54) ${ }^{9}$. Es darf uns nicht genügen, lediglich die medizinische Betreuung der Alten und Kranken sicherzustellen, um uns dann von ihnen wieder zurückzuziehen. Wir müssen nach Wegen suchen, wie Kranke und Alte weiter in der ihnen vertrauten Gemeinschaft bleiben können, bis sie wieder gesund sind oder bis ihr Leben abgeschlossen ist. Wo die konkreten Gegebenheiten eine solche Lösung unmöglich machen, sollten wir wenigstens dafür sorgen, dass diese Menschen in enger Verbindung mit ihrem bisherigen Lebenskreis bleiben können ${ }^{10}$. Wir dürfen uns unseren menschlichen Verpflichtungen nicht mit dem Hinweis entziehen, dass die „Verhältnisse nun einmal so sind“, denn es ist ja unsere Aufgabe, entsprechende menschliche Verhältnisse zu schaffen. Franziskus stellt fest, dass es ohne Frage heute unmenschlich ist, die nicht mehr leistungsfähigen Mitmenschen ohne Not in die Isolierung zu drängen und den Kontakt mit ihnen auf das unumgänglich Notwendige zu beschränken, wie das heute oft geschieht (vgl. EG 14) $)^{11}$.

7 Vgl. Jan Paweł II, List do osób w podesztym wieku (01.10.1999), Nr 9; D. Lipski, Świadectwo życia ludzi chorych, starych i niepetnosprawnych, in: Świadectwo w stużbie ewangelizacji, hrsg. W. Przygoda, Lublin 2012, S. 216.

${ }^{8}$ Vgl. Franciszek, ,Najcięższa choroba, na jaka sq narażone osoby starsze, jest opuszczenie”, op. cit., S. 28; D. Lipski, Świadectwo życia ludzi chorych, op. cit., S. 223; M.E. Czacka, O cierpieniu, in: Wypisy tyflologiczne, Bd. 2, hrsg. C. Gawrysiak, Warszawa 1977, S. 93-96.

9 Vgl. Franciszek, ,Boże miłosierdzie nikogo nie wyklucza”. Przesłanie wygłoszone podczas audiencji dla polskich biskupów przybytych do Watykanu z wizyta ,, ad limina Apostolorum " (7 II 2014), OsRomPol 35 (2014), Nr 2, S. 29; Ders., „Prawdziwq rewolucja jest wspótczucie”. Przemówienie do Wspólnoty św. Idziego, OsRomPol 35 (2014), Nr 7, S. 19; K. Święs, Aktualne uwarunkowania nowej ewangelizacji, in: Polskie drogi nowej ewangelizacji, hrsg. K. Święs, D. Lipiec, Lublin 2014, S. 29.

${ }^{10}$ Vgl. Franciszek, „, Musimy się bronić przed kulturq odrzucania”, op. cit., S. 28-29.

${ }^{11}$ Vgl. Franciszek, ,Ludzie starsi to my”. Audiencja generalna 4 marca 2015, OsRomPol 36 (2015), Nr. 3-4, S. 39-40; Ders., Skażeni przez kulturę odrzucania, OsRomPol 34(2013), 
Papst Franziskus ist der Überzeugung, dass die gegenwärtigen Zustände in der Kranken- und Altenversorgung uns zu einem Umdenken veranlassen müssten. Es wird Zeit, dass wir von der vor allem durch die Konsumgüterindustrie und ihre Werbung propagierten Überbewertung der Jugend, sowie vom Leistungs- und Erfolgsdenkens abkommen und neu erkennen, dass ein volles Menschenleben alle Reifestufen umfasst. Wir müssen es wieder - laut Papst Franziskus - innerlich akzeptieren, dass Krankheit und Alter zum menschlichen Dasein gehören und dass sie uns die Möglichkeit geben, reifer und weiser zu werden ${ }^{12}$. Diese Einsicht ist die Voraussetzung dafür, dass wir auch in den Kranken und Alten vollwertige Mitglieder der Gesellschaft sehen können und bereit sind, ihre berechtigten Ansprüche auf Kommunikation zu achten und mit allen Mitteln versuchen, dem Rechnung zu tragen ${ }^{13}$.

Hier erhebt sich - laut Franziskus - nun die Frage, ob die Christen nicht klarer ihren Standpunkt vertreten und sich intensiver für das uneingeschränkte Lebensrecht all derer einsetzen müssten, die nicht mehr jung, gesund und „fit" sind. Wäre es nicht ihre Pflicht - wo immer das sinnvoll und zielführend erscheint darauf hinzuweisen, dass auch zum Leben des postmodernen Menschen die Erfahrung von Alter, Krankheit und Tod gehört und dass wir alles in unseren Kräften Stehende tun müssen, damit der Mitmensch diese Erfahrungen unter menschenwürdigen Umständen machen kann, das heißt: nicht ausgestoßen aus der Pfarrgemeinschaft, sondern mitten in ihr? Ungläubige mögen verständlicherweise die Begegnung mit Alter, Krankheit und Tod scheuen. Franziskus verweist zu Recht darauf, dass der Christ dieser Konfrontation nicht auszuweichen braucht, denn er weiß um die verschiedenen Lebensphasen als Schritte auf dem Weg ins vollkommene Leben ${ }^{14}$.

Nr. 8-9, S. 48-49; J. Wanke, Neue Herausforderungen - Bleibende Aufgaben. Helfer brauchen Rückhalt, Freiburg i. Br. 1992, S. 112 ff.; R. Biel, Wewnatrzkościelne przyczyny kryzysu wiary, in: Duszpasterstwo wobec kryzysu wiary, hrsg. W. Przygoda, K. Święs, Lublin 2013, S. 95-96; W. Sadłoń, Determinanty funkcjonowania opiekuńczej wspólnoty lokalnej: aktywność parafii w Polsce na rzecz chorych, „Polityka Społeczna” (2012), Nr. 5-6, S. 25-26.

12 Vgl. Franciszek, Najbliższy szpital, op. cit., S. 48-49; Ders., „,Musimy się bronić przed kulturq odrzucania”, op. cit., S. 28-29; Ders., „Dzieci i dziadkowie sq nadzieja ludu”, op. cit., S. 28; D. Lipski, Świadectwo życia ludzi chorych, op. cit., S. 212-215.

${ }^{13}$ Vgl. Franciszek, „Musimy się bronić przed kulturq odrzucania”, op. cit., S. 28-29; Ders., „Ziemia, mieszkanie i praca prawami wszystkich”. Przemówienie do uczestników światowego spotkania ruchów ludowych (28 X 2014), OsRomPol 35 (2014), Nr 11, S, 46; H. Matusiewicz, Opcja preferencyjna na rzecz ubogich i odepchniętych kluczowym aspektem obchodu Jubileuszu, in: Te Deum laudamus. Program duszpasterski na Wielki Jubileusz Roku 2000, hrsg. E. Szczotok, R. Kempny, A. Liskowacka, Katowice 1999, S. 283-293; D. Lipski, Świadectwo życia ludzi chorych, op. cit., S. 217.

${ }_{14}$ Vgl. Franciszek, Najbliższy szpital, op. cit., S. 48-49; F. Bujak, Cierpienie, in: Encyklopedia katolicka, Bd. 3, op. cit., Folge 476; S. Witek, Cierpienie. Aspekt aksjologiczny, in: Encyklopedia katolicka, Bd. 3, op. cit., Folge 480-481; R. Rak, Chrześcijańska postawa wobec cierpienia, „Śląskie Studia Historyczno-Teologiczne” 33(2000), S. 268; D. Lipski, Świadectwo życia ludzi cho- 


\section{Die Bedeutung der christlichen Gemeinde für die kranken und alten Menschen}

Es wäre Franziskus auch zuzustimmen, dass die Haltung einer Kirchengemeinde zu ihren Senioren und Kranken erkennen lässt, inwiefern sie sich faktisch für alle ihre Angehörigen zuständig weiss ${ }^{15}$. Wo man die Behinderten und nicht mehr so Arbeitsfähigen nur als eine Randgruppe betrachtet, der gegenüber man bestimmte Aufgaben hat, die man als Christ wohl oder übel erledigen muss, unterscheidet sich die Sichtweise der Gemeinde nicht von jener, die zum großen Teil in der postmodernen Gesellschaft vertreten wird. Nach christlicher Ansicht aber sind die im Leben und im Glauben bewährten Personen bis zu ihrem Ende vollwertige Angehörige der Pfarrgemeinschaft (vgl. Sir 8,9). Deswegen müsste es außer Diskussion stehen, dass man diesen Menschen einerseits in ihrer besonderen Lage zur Seite steht und sie im Hinblick auf ihre physische und seelische Situation schont, dass man aber andererseits auch von ihnen verlangt und akzeptiert, was sie in diesem Augenblick zu geben haben ${ }^{16}$.

Papst Franziskus zufolge kann sich eine christliche Pfarrgemeinde nur da artikulieren, wo wahrhaftig einer für den anderen da ist, wo also ein angeregter Austausch erfolgt. Schafft man in den Gemeinden Gelegenheiten, dass jugendliche und gesunde Menschen mit Behinderten und in die Jahre Gekommenen ungezwungen zusammenkommen können, um sich kennen- und verstehen zu lernen, so ist das für alle ein Gewinn ${ }^{17}$. Laut Franziskus erlangen die jungen Leute so ein realistisches Bild der menschlichen Existenz und werden zugleich ermutigt, unangemessene Ansichten über die Seniorenzeit zu korrigieren. Wenn Jugendliche die Möglichkeit haben, sich zu überzeugen, dass man bei betagten Menschen Einfühlungsvermögen, Beharrlichkeit, Erkenntnis und Lebensweisheit entdecken

rych, op. cit., S. 217; A. Ołów, Choroba, uzdrowienie, odpuszczenie grzechów, „Communio” (1998), Nr 3, S. 23-24.

${ }^{15}$ Vgl. Franciszek, „Ludzie starsi to my”, op. cit., S. 40; Ders., Najbliższy szpital, op. cit., S. 48-49; D. Lipski, Świadectwo życia ludzi chorych, op. cit., S. 220-221; Z. Zimowski, Postuga dla chorych. Wypowiedź wygłoszona podczas XIII Zwyczajnego Zgromadzenia Ogólnego Synodu Biskupów, OsRomPol 33(2012), Nr 12, S. 19.

${ }^{16}$ Vgl. Franciszek, „Panie, daj nam zaznać świętego upojenia”. Dialog Papieża z kapłanami, młodzieża, rodzinami i osobami niepetnosprawnymi, ORomPol 35 (2014), Nr 7, S. 28; Ders., ,Nikt nie jest wykluczony". Modlitwa maryjna z Papieżem, OsRomPol 35 (2014), Nr, S. 11, 59; A. Kiciński, Niepetnosprawny, in: Encyklopedia katolicka, Bd. 13, Lublin 2009, Folge 1153; W. Chudy, Sens filozoficzny kondycji człowieka niepetnosprawnego, in: Osoba niepetnosprawna i jej miejsce w społeczeństwie, hrsg. D. Kornas-Biela, Lublin 1988, S. 106-108; T. Wielebski, Sakrament namaszczenia chorych $w$ duszpasterskiej posłudze Kościoła, „Słowo Krzyża” 1 (2007), S. 129-143.

17 Vgl. Dokument Stolicy Apostolskiej na Międzynarodowy Rok Osób Upośledzonych, „Ateneum Kapłańskie" 103 (1984), Heft 1, S. 10; D. Lipski, Świadectwo życia ludzi chorych, op. cit., S. 224-225; R. Kamiński, Diecezja i parafia miejscem pastoralnej postugi względem chorych i cierpiacych, „Śląskie Studia Historyczno-Teologiczne” 33(2000), S. 273-281. 
kann, werden sie wahrscheinlich ihr Jungsein nicht überbewerten ${ }^{18}$. Wo man Gebrechliche und Leidende zwangslos und ohne unpassende Überheblichkeit akzeptiert, verschwindet - nach Franziskus - die so weit verbreitete Angst vor den Beschwerden des Alters. So werden die Jugendlichen lernen, entschlossen und mit Hoffnung ihrem eigenen Alter entgegenzusehen ${ }^{19}$. Sie haben es dann nicht nötig, die Vorstellungen von der letzten Phase des Lebens zu verdrängen. Eine korrekt gestaltetes Gemeindeleben, in das auch die alten und kranken Menschen einbezogen sind, kann wesentlich zu einer ausgewogenen Lebensgestaltung aller Gläubigen beisteuern. Es kann auch Vorbild sein für das Verhalten der Gesellschaft den Betagten und Kranken gegenüber ${ }^{20}$.

\section{Gesprächsziele des Seelsorgesprächs}

Betagte und leidende Personen haben ein besonderes Anrecht auf das seelsorgliche Gespräch ${ }^{21}$, das geistlich gestaltet und unterstützt werden soll ${ }^{22}$. Nach Franziskus sollen wir für die Leute beten, bevor wir mit ihnen reden und - wenn man so formulieren darf - auch während wir mit ihnen sprechen. Wir müssen um Unterstützung bitten, damit wir ihnen gerecht werden, und damit wir nie unseren Erfolg, sondern ihr Glück suchen. Eine Besuchsseelsorge kann nur gut gehen, wenn sie von der Meinung getragen wird, dass es letztlich der Heilige Geist ist, der uns die Worte eingibt, die wir benötigen, und der dem Gesprächspartner die Aufnahmebereitschaft gibt, das anzunehmen, was ihm dient. Dazu braucht es das Gebet. Das seelsorgliche Gespräch ist ein geistliches Geschehen; es wird sich - wie letztlich alles seelsorgliche Tun - nicht durch geplante Tricks, sondern durch den Glauben an Gottes Wirksamkeit als fruchtbar erweisen ${ }^{23}$.

Das seelsorgliche und geistliche Gespräch mit den kranken und alten Menschen ist - nach Franziskus - im Bereich der Pfarre eine Herausforderung für

${ }_{18}$ Vgl. Franciszek, „Ludzie starsi to my”, op. cit., S. 40; Z. Zimowski, Na drodze człowieka cierpiqcego. Bóg nawiedził lud swój, Lublin 2013, S. 53-57.

19 Vgl. Franciszek, ,Najcięższq choroba, na jakq sq narażone osoby starsze, jest opuszczenie", op. cit., S. 28.

${ }^{20}$ Vgl. Franciszek, „Ludzie starsi to my”, op. cit., S. 40; Ders., „Ziemia, mieszkanie i praca prawami wszystkich”, op. cit., S. 44-46; D. Lipski, Świadectwo życia ludzi chorych, op. cit., S. 221-222; A. Wollbold, Handbuch, op. cit., S. 395-396.

${ }^{21}$ Vgl. H. Faber, E. Van der Schoot, Praktikum des seelsorglichen Gesprächs, Göttingen 1972, S. 127 ff.; J. Patton, Art. „Pastoral Counseling”, in: Dictionary of Pastoral Care and Counseling, Hg. H.J. Rodney, Nashville 1976, S. 849-854; A. Wollbold, Handbuch, op. cit., S. 397-399.

22 Vgl. Sakrament chorych. Obrzędy i duszpasterstwo, Katowice 1998, Nr 4; T. Wielebski, Duszpasterska postuga Kościoła umocnieniem wiary chorych, in: Duszpasterstwo wobec kryzysu, op. cit., S. 313-314.

${ }^{23} \mathrm{Vgl}$. Franciszek, ,Najcięższq choroba, na jakq sq narażone osoby starsze, jest opuszczenie”, op. cit., S. 28; D. Lipski, Świadectwo życia ludzi chorych, op. cit., S. 212; A. Wollbold, Handbuch, op. cit., S. 401-402. 
jeden Christen, vor allem aber für den Seelsorger (vgl. Mt 10,7-8) ${ }^{24}$. Die pastorale Praxis zeigt, dass er Ausdauer braucht, er muss warten und zuhören können. Darüber hinaus sollte sich der Seelsorger um eine Sprache bemühen, in der das Gemeinte vom Kranken auch faktisch verstanden werden kann. Es wäre zu einfach, von den Geheimnissen des Lebens und des Todes nur in Bildern und Formeln zu reden, die ihm undurchschaubar bleiben und die er nicht mit der Realität, wie er sie erfährt, in Verbindung zu bringen vermag. Wenn alte und kranke Menschen dem Pfarrseelsorger gegenüber argwöhnisch sind und die Verbindung mit ihm zurückweisen, so liegt der Grund dafür oft in der Angst, dass sie auf die sie bedrängenden Schwierigkeiten Antworten bekommen, die ihnen nicht weiter helfen. Sie wollen nicht Schriftworte und Katechismuslehren geboten bekommen, die an dem vorbeizugehen scheinen, was sie an Fragen bedrängt. Mit einem solch unpersönlichen formelhaften Redestil leistet man vor allem dem noch Suchenden keine Hilfe ${ }^{25}$.

Die Frage nach dem Sinn des Lebens und des Todes stellt sich jedem, der das Ende seines Daseins vor Augen hat. Er möchte Klarheit darüber gewinnen, ob sein Leben Bedeutung hat, sowohl für ihn selbst wie für andere. Er verlangt danach, dass sein Leben in einen größeren Zusammenhang, in eine sinnvolle Ordnung eingebunden ist, dass es Wert und Ziel hat ${ }^{26}$. Der Gedanke, dass es nichtig sie könnte, wird angesichts des Todes unerträglich. Getaufte machen oft erst jetzt den Versuch, ernsthaft zum Kern der christlichen Botschaft vorzudringen; ihnen muss man helfen. Viele, die der Kirche fernstanden und früher bezweifelt haben, dass das Leben einen Sinn hat, beginnen nun Fragen zu stellen. Viele, für die der Tod bis dahin ganz selbstverständlich das endgültige Ende des Lebens zu sein schien, möchten nun hoffen und glauben können. Ihnen kann man nur beistehen, wenn man sich bemüht, sich in się hineinzuversetzen und in ihrer Sprache zu sprechen. Vor allem ist falsche Sicherheit da nicht am Platz, wo es um die letzten Geheimnisse geht. Selbst der Geistliche sollte - nach Franziskus - sich

\footnotetext{
${ }^{24}$ Vgl. Franciszek, ,,Musimy się bronić przed kultura odrzucania”, op. cit., S. 29; Ders., „Jezus zbawia, troszczy się, uzdrawia". Modlitwa maryjna z Papieżem, OsRomPol 36 (2015), Nr. 3-4, S. 46; Papieska Rada ds. Duszpasterstwa Służby Zdrowia, Formacja kapłańska a duszpasterstwo stużby zdrowia, Watykan 1991, S. 27-31; I. Celary, Die Verantwortung der Priester für neue geistliche Berufungen, in: Odpowiedzialność w przestrzeni społeczno-pastoralnej, hrsg. I. Celary, G. Polok, Katowice 2013, S. 306-307; T. Wielebski, Duszpasterska posługa Kościoła, op. cit., S. 318-319.

${ }_{25}$ Vgl. M. Klessmann, Handbuch der Krankenhausseelsorge, Göttingen 1996, S. 16-17; A. Wollbold, Handbuch, op. cit., S. 403-404.

${ }^{26}$ Vgl. Katechismus der Katholischen Kirche, Oldenburg 1993, Nr 1501; R. Rak, Chrześcijańska postawa, op. cit., S. 268; S. Witek, Choroba. Aspekt religijno-moralny, in: Encyklopedia katolicka, Bd. 3, op. cit., Folge 235; D. Lipski, Świadectwo życia ludzi chorych, op. cit., S. 213; A. Wollbold, Handbuch, op. cit., S. 396-397.
} 
nicht scheuen zuzugeben, dass es auch für ihn offene Fragen gibt; er gewinnt dadurch an Glaubwürdigkeit ${ }^{27}$.

Der gläubige Mensch ist der Wahrheit verpflichtet. Eben in diesem Moment darf er deswegen dem Gespräch über das Sterben nicht aus dem Weg gehen. Jeder Mensch kommt einmal dahin, dass er sich mit der Gewissheit seines Lebensendes befassen muss. Viele erhoffen sich, in Gelassenheit über den Tod sprechen zu dürfen, finden aber keinen Menschen für ein solches Gespräch ${ }^{28}$. Wenn Verwandte, Freunde und Bekannte diesem Thema ausweichen - sie tun es im allgemeinen besonders dann, wenn das Ende demnächst zu erwarten ist - müsste der Christ, zumindest aber der Seelsorger kompetent sein, so über das Sterben und das neue Leben zu sprechen, dass der Kranke und Betagte mit innerer Ruhe und Hoffnung der Zukunft entgegensehen kann. Zu selten wird heute in der kirchlichen Verkündigung gezeigt, dass Tod und Leben untrennbar zusammengehören, dass wir in jeder Lebensperiode und in jeder Stunde mit dem Tod leben. Deswegen ist es - laut Franziskus - so ernst, den Kranken und Alten hinzuweisen, dass der Tod nicht als ein fremdes, drohendes Erlebnis auf sie zukommt, sondern dass das Sterben jene äußerste Tat der Hingebung ist, auf die sie sich durch Hingabe, durch Selbstlosigkeit und den Glauben an die Erlösung ihr Leben lang vorbereitet haben ${ }^{29}$.

Nach Meinung des Papstes Franziskus braucht der betagte oder leidende Christ ständig neu die Bestätigung, dass seine Existenz für andere, für die Pfarrgemeinde und die gesamte Kirche noch von Wert ist ${ }^{30}$. Er soll durch sein stellvertretendes und fürbittendes Gebet etwas für seine Nächsten und im besonderen für die Kirche tun. Oft fällt es ihm aber schwer, sich auf das Gebet zu konzentrieren, und er hält es für ein Versagen, dass er nicht tun kann, was er tun möchte. Man muss ihm infolgedessen begreiflich machen, dass das Wohl-Wollen, das gute Vorhaben, die innere Anteilnahme am Leben, an den Fragen und Schwierigkeiten der Pfarrgemeinschaft von entscheidender Bedeutung ist. Auch gilt es, ihn zu der Erkenntnis zu führen,

\footnotetext{
${ }^{27}$ Vgl. Franciszek, „Panie, daj nam zaznać świętego upojenia”, op. cit., S. 28; T. Wielebski, Duszpasterstwo chorych w parafii, ,Roczniki Teologiczne Warszawsko-Praskie” 4(2002), S. 135-164.

${ }^{28}$ Vgl. K.J. Ludwig, Kraft und Ohnmacht des Glaubens. Seelsorgliche Begleitung in der Krise der Krankheit, Mainz 1988, S. 32-54.

${ }^{29}$ Vgl. Franciszek, ,Słowo krzyża odpowiedziq na zło”. Rozważanie na zakończenie Drogi Krzyżowej w Wielki Piatek, OsRomPol 34(2013), Nr 5, S. 38; Ders., Przestanie z okazji wystawienia świętego Całunu, OsRomPol 34(2013), Nr 5, S. 39; D. Kornas-Biela, Osoba niepetnosprawna, chora, cierpiaca: nauczanie Jana Pawła II, in: Rodzina: źródło życia i szkoła miłości, Hg. D. Kornas-Biel, Lublin 2000, S. 366; D. Lipski, Świadectwo życia ludzi chorych, op. cit., S. 217.

${ }^{30}$ Vgl. Franciszek, ,W historii miłości”. Homilia podczas Mszy św. w Domu św. Marty (23.04.2013), OsRomPol 34(2013), Nr 6, S. 28-29; Ders., Najbliższy szpital, op. cit., S. 49; Ders., „Musimy się bronić przed kultura odrzucania”, op. cit., S. 28-29; W. Przygoda, Postuga charytatywna droga nowej ewangelizacji, in: Polskie drogi, op. cit., S. 104; S. Witek, Cierpienie, op. cit., Bd. 3, Folge 480-481; D. Lipski, Świadectwo życia ludzi chorych, op. cit., S. 217.
} 
dass das in Beharrlichkeit getragene Leiden ein Ja zum Willen Gottes, ein Zeichen des Glaubens und des Vertrauens ist.

Das seelsorgliche Gespräch ist - wie Franziskus schreibt - neben der Sakramentenspendung der bedeutendste Dienst, den die Kirche ihren leidenden und bejahrten Angehörigen zu leisten hat (vgl. Röm 8,32) ${ }^{31}$. Deswegen muss man in dieser Lage alles daransetzen, dass diese Hilfe ernstgenommen und in der geeigneten Weise getan wird. Bereits gegenwärtig - und mehr noch in Zukunft wird der Seelsorger - im Sinn der Richtlinien des Papstes Franziskus - dazu Helfer brauchen, insbesondere, da die Annahme der Krankensalbung, die nach der neuen Regelung nun einer größeren Gruppe von Gläubigen gespendet werden kann, durch das individuelle seersorgliche Gespräch vorbereitet werden sollte. Man wird sich bemühen müssen, richtige Helfer zu suchen und sie ordentlich für ihre Funktion vorzubereiten ${ }^{32}$. Die Art, in der eine gute Betreuung verwirklicht werden kann, mag in den einzelnen Pfarrgemeinden verschieden sein. Allgemein lässt sich jedoch sagen, dass wir alle die Stellung der kranken und alten Personen für das Leben der Kirche genauer begreifen müssen ${ }^{33}$.

\section{Abschluss}

Aus den Betrachtungen dieses Artikels wird deutlich, dass die Situation der kranken und alten Menschen in vielen Gemeinden immer schwieriger wird. Papst Franziskus fordert von den Hirten der Kirche, dass sie diesen Menschen in verantwortungsvoller Weise helfen, ihren Platz in der heutigen Gesellschaft zu finden. Die Seelsorger sollen mit den kranken und alten Leuten bei verschiedenen Gelegenheiten pastorale Gespräche führen. Sie sollen sie zu erreichen suchen und deren tägliche Probleme kennenlernen.

Die in diesem Artikel behandelten Themen schöpfen den ganzen Reichtum dieser Problematik keineswegs aus. Aber das ist ein Thema für weitere Arbeiten oder zur vertieften Reflexion über die bereits vorhandene Literatur, auf die sich vorliegende Artikel beruft.

${ }^{31}$ Vgl. Franciszek, ,,Jezus zbawia, troszczy się, uzdrawia”, op. cit., S. 46; A. Wollbold, Handbuch, op. cit., S. 400-403.

${ }^{32}$ Vgl. Papieska Komisja Duszpasterstwa Pracowników Służby Zdrowia, Świeccy w świecie cierpienia i zdrowia, Watykan 1987, S. 21, 25-28, 34-37; T. Wielebski, Duszpasterska postuga Kościoła, op. cit., S. 316-317; A. Wollbold, Handbuch, op. cit., S. 399-400.

${ }^{33}$ Vgl. T. Koszałka, Caritas jako praktyczna realizacja miłosierdzia, in: Naśladować Chrystusa. Program duszpasterski na rok 2003/2004, hrsg. P. Kurzela, A. Liskowacka, Katowice 2003, S. 219-226; T. Wielebski, Psychologiczno-spoteczne podstawy duszpasterstwa chorych, ,Roczniki Teologiczne Warszawsko-Praskie" 2 (2002), S. 241-268. 


\section{Help for elderly and ill people in the postmodern society in the teaching of pope Francis}

\section{Summary}

The situation of the elderly and ill in the contemporary postmodern society constitutes a serious challenge for contemporary societies as well as for pastoral work of the Church. Reflections of Pope Francis describing the fate of the elderly and ill in the contemporary reality are to be found in the above article. The issue has been discussed in the following subsections: "Competences of the postmodern society towards the elderly and ill" (chapter I); "The significance of the Christian community for the life of the elderly and ill" (chapter II); "The objectives of the pastoral conversation" (chapter III).

\section{Keywords}

disease, senility, post-modernity, consumerism, teaching, church

\section{Słowa kluczowe}

choroba, starość, postmodernizm, konsumpcjonizm, nauczanie, Kościół

\section{Literatur}

Biel R., Wewnatrzkościelne przyczyny kryzysu wiary, in: Duszpasterstwo wobec kryzysu wiary, hrsg. W. Przygoda, K. Święs, Lublin 2013, S. 79-102.

Bujak F., Cierpienie, in: Encyklopedia katolicka, Bd. 3, Lublin 1993, Folge 476.

Celary I., Die Verantwortung der Priester für neue geistliche Berufungen, in: Odpowiedzialność w przestrzeni spoteczno-pastoralnej, hrsg. I. Celary, G. Polok, Katowice 2013, S. 299-313.

Chudy W., Sens filozoficzny kondycji człowieka niepetnosprawnego, in: Osoba niepetnosprawna i jej miejsce w społeczeństwie, hrsg. D. Kornas-Biela, Lublin 1988, S. 106-108.

Czacka M.E., O cierpieniu, in: Wypisy tyflologiczne, Bd. 2, hrgs. C. Gawrysiak, Warszawa 1977, S. 90-98.

Dokument Stolicy Apostolskiej na Międzynarodowy Rok Osób Upośledzonych, „Ateneum Kapłańskie" 103(1984), Heft 1, S. 10.

Ebertz M.N., Christwerden - in welcher Gesellschaft? Relativiesierungsgeneratoren in der deutschen Gegenwartsgesellschaft, in: Christwerden im Kulturwandel. Analysen, Themen und Optionen für Religionspädagogik und Praktische Theologie, hrsg. T. Schreijäck, Freiburg i. Br. 2001, S. 20-46.

Faber H., Van der Schoot E., Praktikum des seelsorglichen Gesprächs, Göttingen 1972.

Franciszek, Adhortacja apostolska o głoszeniu Ewangelii we współczesnym świecie „Evangelii gaudium”, Częstochowa 2003.

Franciszek, ,,Słowo krzyża odpowiedzia na zło”. Rozważanie na zakończenie Drogi Krzyżowej w Wielki Piatek, OsRomPol 34(2013), Nr. 5, S. 38.

Franciszek, Przestanie z okazji wystawienia świętego Całunu, OsRomPol 34(2013), Nr. 5, S. 39. 
Franciszek, „W historii miłości”. Homilia podczas Mszy św. w Domu św. Marty (23.04.2013), OsRomPol 34(2013), Nr. 6, S. 28-29.

Franciszek, Skażeni przez kulturę odrzucania, OsRomPol 34(2013), Nr. 8-9, S. 48-49.

Franciszek, „Najcięższa choroba, na jakq sq narażone osoby starsze, jest opuszczenie”. Przestanie z okazji 20-lecia Papieskiej Akademii „Pro Vita”, OsRomPol 35(2014), Nr. 3-4, S. 27-28.

Franciszek, „Dzieci i dziadkowie sq nadzieja ludu”. Przemówienie do członków włoskiego Ruchu na rzecz Życia (11.04.2014), OsRomPol 35(2014), Nr. 3-4, S. 27-28.

Franciszek, „Boże miłosierdzie nikogo nie wyklucza”. Przesłanie wygłoszone podczas audiencji dla polskich biskupów przybytych do Watykanu z wizyta ,, ad limina Apostolorum" (7 II 2014), OsRomPol 35(2014), Nr 2, S. 27-29.

Franciszek, „Prawdziwa rewolucja jest współczucie”. Przemówienie do Wspólnoty św. Idziego, OsRomPol 35(2014), Nr. 7, S. 18-20.

Franciszek, „Panie, daj nam zaznać świętego upojenia”. Dialog Papieża z kapłanami, młodzieża, rodzinami i osobami niepetnosprawnymi, OsRomPol 35(2014), Nr. 7, S. 28.

Franciszek, „Ziemia, mieszkanie i praca prawami wszystkich”. Przemówienie do uczestników światowego spotkania ruchów ludowych (28 X 2014), OsRomPol 35(2014), Nr. 11, S. 44-48.

Franciszek, „Nikt nie jest wykluczony”. Modlitwa maryjna z Papieżem, OsRomPol 35 (2014), Nr. 11, S.59.

Franciszek, „Ludzie starsi to my”. Audiencja generalna 4 marca 2015, OsRomPol 36 (2015), Nr. 3-4, S. 39-40.

Franciszek, „Jezus zbawia, troszczy się, uzdrawia”. Modlitwa maryjna z Papieżem, OsRomPol 36(2015), Nr. 3-4, S. 45-46.

Franciszek, ,Wielkie bogactwo społeczne”. Msza św. w parku Los Samanes w Guayaquil (06.07.2015), OsRomPol 36(2015), Nr. 7-8, S. 6-8.

Franciszek, „Musimy się bronić przed kultura odrzucania”. Spotkanie z ludźmi ubogimi, starymi i niepetnosprawnymi, OsRomPol 36(2015), Nr. 7-8, S. 28-29.

Franciszek, Najbliższy szpital, OsRomPol 36(2015), Nr. 7-8, S. 48-49.

Jan Paweł II, List do osób w podeszłym wieku (01.10.1999.), OsRomPol 20(1999), Nr. 12, S. S. 4-11.

Kamiński R., Diecezja i parafia miejscem pastoralnej postugi względem chorych i cierpiacych, „Śląskie Studia Historyczno-Teologiczne” 33(2000), S. 273-281.

Katechismus der Katholischen Kirche, Oldenburg 1993.

Kiciński A., Niepetnosprawny, in: Encyklopedia katolicka, Bd. 13, Lublin 2009, Folge 1153.

Klessmann M., Handbuch der Krankenhausseelsorge, Göttingen 1996.

Koch K., Die Kirche Gottes. Gemeinschaft im Geheimnis des Glaubens, Augsburg 2007.

Kornas-Biela D., Osoba niepetnosprawna, chora, cierpiaca: nauczanie Jana Pawta II, in: Rodzina: źródło życia i szkoła miłości, hrsg. D. Kornas-Biela, Lublin 2000, S. 357-384 . 
Koszałka T., Caritas jako praktyczna realizacja miłosierdzia, in: Naśladować Chrystusa. Program duszpasterski na rok 2003/2004, hrsg. P. Kurzela, A. Liskowacka, Katowice 2003, S. 219-226.

Lipski D., Świadectwo życia ludzi chorych, starych i niepetnosprawnych, in: Świadectwo w stużbie ewangelizacji, hrsg. W. Przygoda, Lublin 2012, S. 211-228.

Ludwig K.J., Kraft und Ohnmacht des Glaubens. Seelsorgliche Begleitung in der Krise der Krankheit, Mainz 1988.

Matusiewicz H., Opcja preferencyjna na rzecz ubogich i odepchniętych kluczowym aspektem obchodu Jubileuszu, in: Te Deum laudamus. Program duszpasterski na Wielki Jubileusz Roku 2000, hrsg. E. Szczotok, R. Kempny, A. Liskowacka, Katowice 1999, S. 283-293.

Ołów A., Choroba, uzdrowienie, odpuszczenie grzechów, „Communio” (1998), Nr 3, S. $17-30$.

Papieska Komisja Duszpasterstwa Pracowników Służby Zdrowia, Świeccy w świecie cierpienia i zdrowia, Watykan 1987.

Papieska Rada ds. Duszpasterstwa Służby Zdrowia, Formacja kapłańska a duszpasterstwo stużby zdrowia, Watykan 1991.

Patton J., Art. „Pastoral Counseling”, in: Dictionary of Pastoral Care and Counseling, hrsg. H.J. Rodney, Nashville 1976, S. 849-854.

Pietrasiński Z., Rozwój dorostych, in: Wprowadzenie do andragogiki, hrsg. T. Wujek, Radom 1996, S. 28-35.

Przygoda W., Teologia cierpienia i choroby, „Śląskie Studia Historyczno-Teologiczne” 33(2000), S. 257-266.

Przygoda W., Postuga charytatywna Kościoła wobec osób niepetnosprawnych, „Homo Dei" 74(2004), Nr. 1, S. 59-70.

Przygoda W., Die karitative Praxis der Kirche in Polen am Anfang des 21. Jahrhunderts, in: Pastoral-theologische Hefte, Bd. 1, hrsg. M. Polak, T. Kowalczyk, Wien-Gniezno 2008, S. 94-98.

Przygoda W., Postuga charytatywna droga nowej ewangelizacji, in: Polskie drogi nowej ewangelizacji, hrsg. K. Święs, D. Lipiec, Lublin 2014, S. 75-105.

Rak R., Chrześcijańska postawa wobec cierpienia, „Śląskie Studia Historyczno-Teologiczne" 33(2000), S. 267-272.

Sadłoń W., Determinanty funkcjonowania opiekuńczej wspólnoty lokalnej: aktywność parafii w Polsce na rzecz chorych, „Polityka Społeczna” (2012), Nr. 5-6, S. 25-26.

Sakrament chorych. Obrzędy i duszpasterstwo, Katowice 1998.

Strojnowski J., Choroba, in: Encyklopedia katolicka, Bd. 3, Lublin 1993, Folge 232-235.

Święs K., Aktualne uwarunkowania nowej ewangelizacji, in: Polskie drogi nowej ewangelizacji, hrsg. K. Święs, D. Lipiec, Lublin 2014, S. 21-56.

Wanke J., Neue Herausforderungen - Bleibende Aufgaben. Helfer brauchen Rückhalt, Freiburg i. Br. 1992.

Wielebski T., Psychologiczno-społeczne podstawy duszpasterstwa chorych, „Roczniki Teologiczne Warszawsko-Praskie" 2(2002), S. 241-268. 
Wielebski T., Duszpasterska postuga Kościoła w szpitalach $i$ hospicjach, „Roczniki Teologiczne Warszawsko-Praskie" 3(2002), S. 265-298.

Wielebski T., Duszpasterstwo chorych w parafii, „Roczniki Teologiczne Warszawsko-Praskie" 4(2002), S. 135-164.

Wielebski T., Sakrament namaszczenia chorych $w$ duszpasterskiej postudze Kościoła, „Słowo Krzyża” 1(2007), S. 129-143.

Wielebski T., Duszpasterska postuga Kościoła umocnieniem wiary chorych, in: Duszpasterstwo wobec kryzysu wiary, hrsg. W. Przygoda, K. Święs, Lublin 2013, S. 309-337.

Witek S., Choroba. Aspekt religijno-moralny, in: Encyklopedia katolicka, Bd. 3, Lublin 1993, Folge 235.

Witek S., Cierpienie. Aspekt aksjologiczny, in: Encyklopedia katolicka, Bd. 3, Lublin 1993, Folge 480-481.

Wollbold A., Handbuch der Gemeindepastoral, Regensburg 2004.

Zimowski Z., Postuga dla chorych. Wypowiedź wygłoszona podczas XIII Zwyczajnego Zgromadzenia Ogólnego Synodu Biskupów, OsRomPol 33(2012), Nr 12, S. 19.

Zimowski Z., Na drodze czlowieka cierpiqcego. Bóg nawiedzit lud swój, Lublin 2013. 